\title{
The differential effects of timeout and shock on DRL responding in the CER paradigm
}

\author{
B. KENT PARKER, DAN L. BARKER, and JEFF TOPPING* \\ University of Portland, Portland, Oreg. 97203
}

A within-Ss design with hooded rats and a DRL 10 -sec reinforcement schedule was used to study the effects of timeout (TO) and shock on baseline responding in the CER paradigm. Results indicated that all Ss accelerated responding during the preTO stimulus and suppressed responding during the preshock stimulus. Although the findings with shock were consistent with those of previous investigations, the results with TO were exactly the opposite of those obtained in earlier studies with rats.

Estes \& Skinner (1941) demonstrated that a stable leverpressing baseline in rats could be reduced upon presentation of a conditioned stimulus (CS) that preceded the presentation of response-independent electric shock. This phenomenon is now referred to as conditioned suppression or the conditioned emotional response (CER). Substantial validity and generality for conditioned suppression can be found in the numerous studies (e.g., Annau \& Kamin, 1961; Blackman, 1968; Hendry \& Von Toller, 1965 ; Hoffman \& Fleshler, 1961; Kamin, Brimer, \& Black, 1963; Lyon, 1963; Stein, Sidman, \& Brady, 1958) which have also discovered decreased response rates during a preshock stimulus. Related to the CER studies are many experiments (e.g., Leaf, 1964; LoLordo, 1967 ; Moscovitch \& LoLordo, 1968; Overmier, 1966; Overmier \& Leaf, 1965; Rescorla, 1967; Rescorla \& LoLordo, 1965) which have (1) established a discriminative Pavlovian CS via pairings with the presence or absence of shock and (2) shown that presentations of just the CS can have a very powerful effect on operant response rates (e.g., in Sidman avoidance).

Recently, attention has focused on whether or not responding maintained by positive reinforcement would be suppressed during a stimulus preceding and terminating with an aversive event other than electric shock in the CER paradigm. This aversive event, referred to as timeout (TO) from positive reinforcement, is defined as a time period during which previously available positive reinforcement is no longer available. Evidence as to the aversiveness of $\mathrm{TO}$ has been obtained from many different experimental situations and has been reviewed by Leitenberg (1965).

* Requests for reprints should be sent to Jeff S. Topping, P.O. Drawer PF, Mississippi State University, State College, Miss. 39762.
Regarding the use of $\mathrm{TO}$ as the aversive event in the CER paradigm, very few studies exist and results to date have been contradictory and confounded. An unpublished doctoral thesis by Herrnstein (1955) appears to have been the first study concerned with the effects of a preTO stimulus on the operant baseline response rate. Using pigeons, numerous variable-interval (VI) schedules of $r$ e inforcement, and a response-contingent situation, Herrnstein found that response rates were suppressed during the preTO CS when reinforcement frequency was high but accelerated when reinforcement frequency was low. Ferster (1958) employed a similar paradigm and observed that chimpanzees and pigeons accelerated responding during the $C S$ when reinforcement was produced on VI 3 and VI 6 schedules, respectively.

Since these two studies using TO and a response-contingent paradigm, emphasis has shifted to the more "typical" procedure in which the aversive event occurs independently of a response. For example, Leitenberg $\left(\begin{array}{ll}1966) & \text { us ed both the }\end{array}\right.$ response-independent and response-contingent procedures with pigeons to compare the effects of preshock and preTO stimuli on responding reinforced according to a VI 2-1/3 schedule. Leitenberg witnessed conditioned suppression during the preshock CS and conditioned acceleration during the preTO CS, regardless of whether the aversive event was contingent or independent of responding. Similarly, Trenholme, Baron, \& Kaufman (1969) found acceleration during a preTO CS when human $\mathrm{Ss}$ were reinforced on a VI 1-1/3 schedule. However, Leitenberg, Bertsch, \& Coughlin (1968) employed TO with rats and a VI 7 reinforcement schedule and observed conditioned suppression. Leitenberg et al even manipulated such variables as deprivation conditions, reinforcement schedule, TO duration, and type of CS in an attempt to produce conditioned acceleration in rats, but such efforts were unsuccessful. In addition, Carman (1969) and Kaufman (1969) obtained suppressed responding during a preTO $\mathrm{CS}$ with rats on VI $30-$ and VI $15-\mathrm{sec}$ schedules, respectively.

From this brief review it is obvious that procedural differences between experiments precludes the identification of the necessary conditions for producing conditioned acceleration and/or conditioned suppression with TO. In addition, differences in species seem to be very important, since the typical finding of conditioned acceleration has never been observed with rats, and this fact prompted the present experiment.

The three previously mentioned studies with rats employed VI 7-, VI $30-$, and VI 15-sec reinforcement schedules, respectively. Although response rate was not controlled directly in any of these experiments, it seems safe to assume that the VI 7 schedule generated relatively slow rates, while the VI $30-$ and VI $15-\mathrm{sec}$ schedules produced relatively fast rates. Therefore, Ss with the VI 7 schedule had a low-reinforcementfrequency / low-response-rate combination, whereas Ss on the VI 30and VI 15-sec schedules were exposed to high-reinforcement-frequency/highresponse-rate conditions. The fact that conditioned acceleration was not observed in any of these cases suggests that the wrong combination of reinforcement and response-rate conditions was being employed. The present study attempted to produce conditioned acceleration in rats by using the previously neglected high-reinforcemen t-frequency/lowresponse-rate combination. Thus, a differential reinforcement of low rate (DRL) 10-sec schedule was chosen because it is known to generate the desired reinforcement and rate conditions.

\section{SUBJECTS}

Eight male hooded rats, individually housed, served as $\mathrm{Ss}$ and were maintained at $80 \%$ of their free-feeding body weights throughout the experiment. All Ss were experimentally naive and were 150 days old at the start of the experiment.

A standard one-lever Gerbrands operant conditioning unit was enclosed within a Grason-Stadler soundproof chamber. The 2-in.-long response lever extended $3 / 4 \mathrm{in}$. in to the experimental compartment and was centered 2 in. above the grid floor on the front wall of the unit. The foodcup was located in the lower 
Table 1

Mean Suppression Ratios During the Final Five Sessions of Each Phase

\begin{tabular}{|c|c|c|c|c|c|c|c|c|}
\hline & \multicolumn{4}{|c|}{ Shock-TO Group } & \multicolumn{4}{|c|}{ TO-Shock Group } \\
\hline & $\mathrm{S} 1$ & S 2 & S 3 & S 4 & S 5 & S 6 & S 7 & S 8 \\
\hline Phase 1 & 0.163 & 0.383 & 0.494 & 0.247 & 1.432 & 1.452 & 1.572 & 1.284 \\
\hline Phase 2 & 1.310 & 1.031 & 1.312 & 1.318 & 0.606 & 0.120 & 0.090 & 0.062 \\
\hline
\end{tabular}

left-hand corner of the front wall, and reinforcement consisted of one $45-\mathrm{mg}$ Noyes pellet. Responses and reinforcement deliveries produced auditory feedback. Centered 2 in. above the response lever were three circular (1-in.-diam) stimulus lights (red, yellow, and green), which were illuminated by $7.5-\mathrm{W}$ light bulbs and spaced 3 in. apart. A small light bulb also helped illuminate the chamber. Electric shock was provided through the grid floor via a Grason-Stadler shock generator. Shock intensity was $.75 \mathrm{~mA}$ and of $0.5 \mathrm{sec}$ duration. A white-noise generator and an air blower functioned throughout the experiment to mask any extraneous sounds and regulate the temperature inside the chamber. Standard electromechanical programming equipment was employed to control experimental events, while data were recorded on digital counters and a cumulative recorder.

\section{PROCEDURE}

On Days 1-5, Ss were magazine trained and shaped (CRF) to press the response lever. On Day 6 Ss were placed on a DRL 10 -sec reinforcement schedule. All $S s$ received 10 days of pretraining on the DRL 10-sec schedule, thus allowing response rates to stabilize during and across sessions.

Following pretraining, all $\mathrm{Ss}$ were given at least 14 more daily sessions on the DRL 10-sec schedule, during which 10 response-independent CS presentations ( 5 red and 5 green) occurred daily without subsequent TO or shock. Throughout the remainder of the experiment, the CS duration was $30 \mathrm{sec}$, from 5 to $9 \mathrm{~min}$ elapsed between CS occurrences, and reinforcements were possible during each CS. In addition, the first CS presentation was delayed $8 \mathrm{~min}$ from the time $S$ entered the experimental apparatus. This adaptation phase continued for each $\mathrm{S}$ until at least one and no more than six responses were emitted during each of the 10 daily CS occurrences (three responses per $30-\mathrm{sec}$ CS would be expected on the DRL 10-sec schedule).

After CS adaptation, Ss were assigned randomly to one of two groups. One group (shock-TO) experienced response-independent electric shocks at the termination of each CS during Phase 1 (20 daily sessions) of training, while the remaining group ( $\mathrm{TO}-\mathrm{shock}$ ) experienced a 4-min TO when the CS terminated. Six CS presentations were programmed daily and half of each group had the red CS and the remainder had green as the signal for shock, and similarly for TO. During Phase 2 (also 20 daily sessions), the groups were switched to the alternative aversive event and CS. When a CS was not in effect, the compartment was illuminated by the center yellow light. During TO periods the stimulus lights were turned off, responses had no programmed effect, and reinforcements were not available. RESULTS

Daily suppression ratios were calculated by dividing the mean number of responses emitted during the CS by the mean number of responses occurring during the $30-\mathrm{sec}$ period preceding the CS; therefore, ratios below 1.00 indicate conditioned suppression and ratios above 1.00 denote conditioned acceleration. Table 1 presents the average ratios for all Ss of both groups over the final five daily sessions of each experimental phase; as indicated, all Ss (except S 2 during TO) exhibited marked conditioned suppression and conditioned acceleration when shock and TO were the respective aversive events. Although cumulative records were not kept, responding during the CS signaling TO occurred at fairly uniform and constant rates, while responses during the $C S$ signaling shock were emitted relatively early in the CS interval.

Analyses of variance were performed over all sessions (in two-session blocks) of both similar in each phase. That is, a significant groups effect was found in each phase $(F=88.46, \quad d f=1 / 6$, $\mathrm{p}<.01$ for Phase 1 and $\mathrm{F}=30.15$, $\mathrm{df}=1 / 6, \mathrm{p}<.01$ for Phase 2) and was due, as previously suggested, to shock $\mathrm{Ss}$ suppressing responding and TO Ss accelerating responding during the CS. In addition, a significant blocks effect ( $\mathrm{F}=3.33, \quad \mathrm{df}=9 / 54, \quad \mathrm{p}<.01$ and $F=3.94, \mathrm{df}=9 / 54, \mathrm{p}<.01)$ and $a$ interaction $\quad(F=8.76, \quad \mathrm{df}=9 / 54$ $\mathrm{p}<.01$ and $F=9.61, \quad \mathrm{df}=9 / 54$, $p<.01$ ) were found.

Two additional analyses were conducted to determine if the two groups suppressed and accelerated responding at similar rates. With experimental phases, and results were significant Groups by Blocks respect to suppression, the groups effect and the Groups by Blocks interaction were both insignificant (Fs $<1)$, and the blocks effect was significant $(F=7.63, \quad \mathrm{df}=9 / 54$, $\mathrm{p}<.01$ ), as expected. With regard to acceleration, the effects of groups $(\mathrm{F}=9.28, \quad \mathrm{df}=1 / 6, \quad \mathrm{p}<.05)$ and blocks $(F=15.45, \mathrm{df}=9 / 54, p<.01)$ were both significant, although the Groups by Blocks interaction was not significant. The significant groups effect was due to the fact that the TO-shock group exhibited greater conditioned acceleration throughout the TO phase than did the shock-TO group.

Previous studies using pigeons (Leitenberg, 1966), chimpanzees (Ferster, 1958), and humans (Trenholme, Baron, \& Kaufman, 1969) as Ss have found accelerated responding during a $C S$ preceding $\mathrm{TO}$ in the CER paradigm, while studies with rats (Carman, 1969; Kaufman, 1969; Leitenberg et al, 1968) have shown suppressed responding under similar circumstances. The present results seem to remove this very puzzling discrepancy since they indicate that conditioned acceleration can be obtained with rats when responding is maintained at a low rate and reinforcement frequency is high. The fact that conditioned suppression was observed when shock was used as the aversive event with these same Ss supports previous outcomes and lends some reliability to the conditioned acceleration result with TO.

The discrepancy between the present findings and those of Carman (1969), Kaufman (1969), and Leitenberg et al (1968) can be resolved if the response rate and reinforcement frequency conditions are compared in these studies. As previously mentioned, the present experiment utilized a low response rate and high reinforcement frequency and found conditioned acceleration. In contrast, the conditioned suppression observed in the previous studies with rats might have been due to the fact that Carman and Kaufman necessarily employed a high response rate and high reinforcement frequency, while Leitenberg et al apparently used a low rate of responding and a low frequency of reinforcement.

The finding of conditioned acceleration during the preTO $\mathrm{CS}$ is even more interesting when one considers the effect of accelerated responding on the number of reinforcements obtained. That is, during adaptation sessions before the introduction of $\mathrm{TO}$, Ss were obtaining nearly the maximum number of reinforcements before and during the 
occurrence of the subsequent preTO CS. Upon the introduction of TO and the development of conditioned acceleration, Ss obtained virtually no reinforcements during the CS. Since the $\mathrm{Ss}$ were receiving no reinforcements during the preTO $\mathrm{CS}$, it seems reasonable that $S$ might decrease their responding during this CS. However, the accelerated responding obtained suggests that the baseline reinforcement and response-rate conditions, together with the TO periods, must have been responsible for this effect.

Research is presently under way in the author's laboratory to investigate further the effects of reinforcement frequency and response rate when $T O$ is used as the aversive event in the CER paradigm.

REFERENCES
ANNAU, Z. \& KAMIN, L. J. The
conditioned emotional response as a
function of intensity of the UCS. Journal
of Comparative \& Physiological
Psychology, 1961, 54, 428-432.
BLACKM AN, D. E. Response rate,
re inforce ment frequency, and
conditioned suppression. Journal of the
Experimental Analysis of Behavior, 1968,
$11,503-516$.

CARMAN, I. B. Time-out from a short mean-interval variable-interval reinforcement schedule. Psychonomic Science, 1969, 15, 259-260.

ESTES, W. K., \& SKINNER, B. F. Some quantitative properties of anxiety. Journal of Experimental Psychology. $1941,29,390-400$.

FERSTER, C. B. Control of behavior in chimpanzees and pigeons by time-out from positive reinforcement. Psychological Monographs, 1958, 72 (Whole No. 461).

HENDRY, D. P., \& VON TOLLER, C. Alleviation of conditioned suppression. Journal of Comparative \& Physiological Psychology, 1965, 59, 458-460.

HER R NTEIN, R. J. Behavioral consequences of the removal of a discriminative stimulus associated with variable-interval reinforcement. Unpublished doctoral thesis, Harvard University, 1955.

HOFFMIAN, H. S., \& FLESHER, M. Stimulus factors in aversive control: The generalization of conditioned suppression. Journal of the Experimental Analysis of Beharior, $1961,4,371-378$.

KAMIN, L, J., BRIMER, C. J. \& BLACK, A H. Conditioned suppression as a monitor of fear of the $C S$ in the course of avoidance training. Journal of Comparative \& Physiological Psychology. $1963,56,497-501$

KAUFMAN, A. Response suppression in the CER paradigm with extinction as the aversive event. Psychonomic Science, $1969,15,15-17$.

$L E A F, R$. C. Avoidance response evocation as a function of prior discriminative fear conditioning under curare. Journal of Comparative \& Physiological Psychology, $1964,58,446-450$.

LEITENBERG, H. Is time-out from positive reinforcement an aversive event? A review of the experimental evidence. Psychological Bulletin, 1965, 64, 428-441.

LEITENBERG, H. Conditioned acceleration and conditioned suppression in pigeons. Journal of the Experimental Analysis of Behavior, 1966, 9, 205-212.

LEITENBERG, H., BERTSCH, G. J., \&
cOUGHLIN R. C. "Time-out from positive reinforcement" as the UCS in a CER paradigm with rats. Psychonomic Science, 1968, 13, 3-4.

LoLORDO, V. M. Similarity of conditioned fear responses based upon different aversive events. Journal of Comparative \& Physiological Psychology, 1967, 64, 154-158.

LYON, D. O. Frequency of reinforcement as a parameter of conditioned suppression. Journal of the Experimental Analysis of Behavior, $1963,6,95-98$.

MOSCOVITCH, A., \& LoLORDO, V. M. Role of safety in the Pavlovian back ward fear conditioning procedure. Journal of Comparative \& Physiological Psychology, $1968,66,673-678$.

OVERMIER, J. B. Instrumental and cardiac indices of Pavlovian fear conditioning as a function of US duration. Journal of Comparative \& Physiological Psychology, 1966, 62, 15-20.

OVERMIER, J. B.. \& LEAF, R. C. Effects of discriminative Pavlovian feat conditioning upon previously or subsequently acquired aroidance responding. Journal of Comparative \& Physiological Psychology , 1965, 60, 213-217.

RESCORT A R. A Inhibition of delay in Paviovian fear conditioning. Journal of Comparative \& Physiological Psychology, 1967, 64, 114-120.

RESCORLA, R. A, \& LOLORDO, V. M. Inhibition of avoidance behavior. Journal of Comparative \& Physiological Psychology, 1965, 59, 406-412.

STEIN, L., SIDMAN, M., \& BRADY, J. V. Some effects of two temporal variables on conditioned suppresssion. Joumal of the Experimental Analysis of Behavior, $1958,1,153-162$.

TRENHOLME, I. A., BARON, A., \& KAUFMAN, A. Effects of signaled time-out from and loss of monetary reinforcement on human operant behavior. Psychonomic Science, 1969, 15. 295-296.

\title{
Spontaneous alternation as investigative behavior*
}

\author{
R. O'CONNELL \\ San Fernando Valley State College, Northridge, Calif. 91324
}

Male rats were tested for spontaneous alternation in a Y-maze with either clear or opague swinging doors separating the goal arms from the choice point. This variation in visual access to the arms did not significantly affect alternation. Choice on Trial 2 was slower with opaque doors.

Sutherland (1957) demonstrated that when Ss are given repeated trials spontaneous alternation (SA) is significantly greater when the choice arms lead to different goalboxes than when the arms turn and end in a common goalbox. He concluded that SA may occur primarily with respect to "the rat's expectancy of the stimuli it will receive beyond the choice point ... [p. 361]." Berlyne (1960) has labeled such responses, which "bring the subject into contact with objects that are not already represented in the stimulus field," "investigative responses." He distinguished them from "inspective responses," which yield "further stimulation from stimulus objects that are already acting on receptors [p. 80]." Berlyne cited the Walker et al (1955) sidewinder-maze study as a second demonstration of investigative exploration, since S's choice was presumably a function of proprioceptive stimuli received after the arm had been selected. In fact, however, the maze was constructed so that the proprioceptive stimulation could be sampled to a degree prior to

* A part of this research was supported by NSF funds through the Committee on Research, UCLA. Heeock R, Kim was responsible for data collection. choice. It also had physically separate choice points for north and south start stems, which would have reduced the availability of odor cues when response cues and intramaze cues were opposed by starting the rat from the opposite start stem on Trial 2. Hence the apparent effect of response discriminability (proprioceptive stimulation) in the sidewinder maze could have been due to the confounding of the attenuation of odor cues with the increase in response discriminability. Possibly more relevant, therefore, is the fact that the maze incidentally restricted visual access to the arms prior to choice and yielded an unusually high $(94 \%)$ alternation when no cues were placed in opposition.

The present experiments were conducted to determine whether SA would be affected if its investigative component were presumably varied by changing the visual availability of the outcomes from the choice point. This was done by using either clear or opaque goal-arm doors. No attempt was made to eliminate odor trail or spatial orientation cues. The question posed was: To what extent do differences on these cue dimensions foster SA, not because the cues of the two arms are differentially attractive 